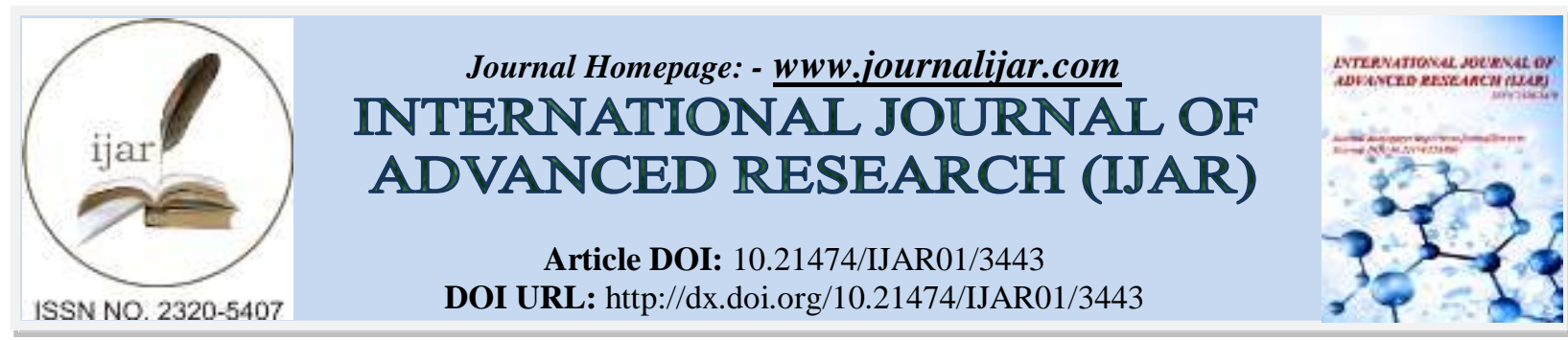

RESEARCH ARTICLE

\title{
THE EFFECTIVENESS OF MUSIC AND MOTHER'S VOICE ON PAIN REDUCTION DURING VENEPUNCTURE IN NEONATES- A RANDOMIZED CONTROL TRIAL
}

\section{Dr. Vadlamudi Haarika, Dr. Palanisamy Soundararajan, Dr. Sumathy Sundar, Dr. Rajaramalingam, Dr. Dhandapani Gunasekaran and Dr. Karuppiah Pandi.}

\section{Manuscript Info}

Manuscript History

Received: 18 December 2016

Final Accepted: 16 January 2017

Published: February 2017

\section{Abstract}

Copy Right, IJAR, 2017,. All rights reserved.

\section{Introduction:-}

Until few decades ago, pain was considered as an inappropriate term for neonates and so pain assessment and management was not part of routine care in NICU.In NICU, neonates are exposed to environment stress. During their stay in the NICU, on an average 14 painful procedures are experienced by neonates during the first 2 weeks of life $^{1}$.Studies have shown that repeated painful stimuli can lower pain threshold in neonates ${ }^{2}$. Repeated painful stimuli alters neurodevelopment and programming of the stress system thereby increasing the pain perception in neonates who are born as preterm ${ }^{3}$. Repeated painful stimuli causes abnormalities in brain maturation which persists through childhood and adolescence leading to adverse neuro developmental outcomes ${ }^{4}$.Hence minimizing pain helps in prevention of occurrence of long term neurological outcome.

Musical intervention acts as a source of distraction and positively affects the distress levels and pain perception in neonates ${ }^{5}$. Studies on the positive effect of mother's voice (infant directed speech/singing) on pain reduction and better oxygen saturation, improvements in heart rate and respiratory rates are also available ${ }^{6,7}$. But studies comparing mother's voice and music are not available in Indian context and so, we studied effectiveness of music and mother's voice (infant directed speech) in pain reduction during venepuncture in neonates.

\section{Methodology:-}

The study was registered in Clinical Trials Registry - India and the Institutional Human Ethics Committee (No: PG/2014/47). After the informed consent was taken this open labeled randomized controlled study was carried out at neonatology unit at Mahatma Gandhi Medical College \& Research Institute (MGMCRI), Pondicherry, South India from January 2014 to December 2014. All neonates undergoing venepuncture in the post natal ward were included in this study. The neonates were in awake state. Neonates 1) with intravenous cannula, 2) critically ill, 3) associated with painful conditions, 4)immunized within $24 \mathrm{hrs}$ were excluded. Total 300 neonates were included in the study. They were divided into music, mother's voice and control groups by block randomization method. Each group consisted of 100 subjects. All the neonates were checked for hearing loss by startle reflex given by them to the auditory stimulus in the form of clapping hands by the investigator. The neonates without any hearing loss were included in the study. The neonates in music group were exposed to pre recordedlullaby 5 minutes before starting the venepuncture and during the procedure of venepuncture. Music was played through music player using 
speakers placed $30 \mathrm{~cm}$ from the neonate. The speaker used was JBL Flip 2 portable wireless stereo speaker with maximum SPL of $86 \mathrm{~dB}$ and frequency response of $100 \mathrm{~Hz}-20 \mathrm{KHz}$. The sound decibel of the music played was checked using Benetech GM 1351digital sound level meter. The volume of the speaker was adjusted such that the NICU environment sound level never exceeded beyond $65 \mathrm{~dB}$.

The neonates in mother's voice group received pre recorded mother's voice [infant directed speech ${ }^{8}$ ] $\mathrm{minutes}$ before and during venepuncture procedure. Both the music group and the mother's voice group received in total 15 minutes of intervention each. The control group received no intervention but received only the standard nursing care during the venepuncture procedure. The pain levels were assessed using NPASS by the investigator. The physiological parameters were assessed by an independent observer. The NPASS was done 5 minutes before, during and 5 minutes after the procedure. NPASS used in our study was commonly used to assess pain response in infants during painful procedures ${ }^{9}$ as the score evaluated 5 parameters - crying, behavioural state, facial expression, extremities tone and vital signs. The heart rate, oxygen saturation were monitored using pulseoximeter and the respiratory rate was counted manually. Minimum and maximum possible scores were -10 and 10 respectively. The investigator also noted the duration of crying spells when neonates started and stopped crying by using a stop clock. No neonate was sedated during the venepuncture procedure. Eight neonates were excluded from this study as they were in sleep state and didn't awake after venepuncture. 292 neonates were analyzed. The other neonates were in awake state during the study.

\section{Statistical Analysis:-}

The results were analyzed by using Kruskal Wallis for comparing all the three groups. Mann Whitney U Test was done for intergroup comparison.

\section{Results:-}

Results of Neonatal pain, agitation and sedation scale (NPASS) for each of five domains crying, behavior state, facial expression, extremities tone and vital signs), 10-point NPASS for music and control groups are shown in table 1. NPASS score of mother' voice and control group are shown in table 2 and mother's voice and music group are shown in table 3.

All five domains of NPASS- vital signs, irritability, facial expression, behavioral state, tone and the total NPASS have shown significant lower pain perception in music group when compared to control group $(\mathrm{P}=0 \cdot 000)$. All the five domains of pain - vital signs, irritability, facial expression, behavior state, tone and the total NPASS were lower in mother's voice group when compared to control group $(p=0 \cdot 000)$. There was significant difference in the heart rate, respiratory rate, facial expression and behavioral state and the total NPASS ( $\mathrm{p}=0 \cdot 000)$ between the mother's voice and music group. Music was better than mother's voice and control group in pain reduction during venepuncture.

Table 1:- Comparison of clinical and behavioural parameters between control and music group

\begin{tabular}{|l|l|l|l|}
\hline Parameter & Group 1 ( Control) & Group 2 (Music) & p value \\
\hline BEFORE INTERVENTION & $0 \cdot 01 \pm 0 \cdot 102$ & $0 \cdot 07 \pm 0 \cdot 412$ & $0 \cdot 316$ \\
\hline NPASS & $1 \cdot 65 \pm 0 \cdot 542$ & $1 \cdot 22 \pm 0 \cdot 682$ & $0 \cdot 000$ \\
\hline DURING INTERVENTION & $0 \cdot 82 \pm 0 \cdot 389$ & $0 \cdot 000$ \\
\hline Vitals signs & $0 \cdot 99 \pm 0 \cdot 102$ & $1 \cdot 20 \pm 0 \cdot 609$ & $0 \cdot 000$ \\
\hline Irritability & $1 \cdot 6 \pm 0 \cdot 513$ & $0 \cdot 73 \pm 0 \cdot 635$ & $0 \cdot 000$ \\
\hline Facial expression & $1 \cdot 51 \pm 0 \cdot 754$ & $0 \cdot 64 \pm 0 \cdot 63$ & $0 \cdot 000$ \\
\hline Behavioral state & $1 \cdot 46 \pm 0 \cdot 767$ & $4 \cdot 62 \pm 2 \cdot 137$ & $0 \cdot 000$ \\
\hline Tone & $7 \cdot 21 \pm 2 \cdot 16$ & & \\
\hline NPASS & $0 \cdot 74 \pm 1 \cdot 028$ & $0 \cdot 55 \pm 0 \cdot 954$ & $0 \cdot 188$ \\
\hline AFTER INTERVENTION & \\
\hline NPASS & & & \\
\hline
\end{tabular}


Table 2:- Comparison of clinical and behavioral parameters between control and mother's voice group

\begin{tabular}{|l|l|l|l|}
\hline Parameter & Group 1 ( Control) & Group 3 (Mother's Voice) & p value \\
\hline BEFORE INTERVENTION & $0 \cdot 01 \pm 0 \cdot 102$ & $0 \cdot 05 \pm 0 \cdot 297$ & $0 \cdot 319$ \\
\hline NPASS & $1 \cdot 65 \pm 0 \cdot 542$ & $1 \cdot 476 \pm 0 \cdot 522$ & $0 \cdot 010$ \\
\hline DURING INTERVENTION & $0 \cdot 99 \pm 0 \cdot 102$ & $0 \cdot 91 \pm 0 \cdot 345$ & $0 \cdot 019$ \\
\hline Vital signs & $1 \cdot 6 \pm 0 \cdot 513$ & $1 \cdot 47 \pm 0 \cdot 502$ & $0 \cdot 052$ \\
\hline Irritability & $1 \cdot 51 \pm 0 \cdot 754$ & $1 \cdot 35 \pm 0 \cdot 644$ & $0 \cdot 021$ \\
\hline Facial expression & $1 \cdot 46 \pm 0 \cdot 767$ & $0 \cdot 74 \pm 0 \cdot 438$ & $0 \cdot 000$ \\
\hline Behavior state & $7 \cdot 21 \pm 2 \cdot 16$ & $5 \cdot 94 \pm 1 \cdot 899$ & $0 \cdot 000$ \\
\hline Tone & $0 \cdot 74 \pm 1 \cdot 028$ & $0 \cdot 64 \pm 1 \cdot 115$ & 0.409 \\
\hline NPASS & \multicolumn{5}{|l|}{} \\
\hline AFTER INTERVENTION &
\end{tabular}

Table 3:- Comparison of clinical and behavioral parameters between music and mother's voice group

\begin{tabular}{|c|c|c|c|}
\hline Parameter & Group 2 (Music) & Group 3 (Mother's voice) & $\mathrm{p}$ value \\
\hline \multicolumn{4}{|c|}{ BEFORE INTERVENTION } \\
\hline NPASS & $0 \cdot 07 \pm 0 \cdot 412$ & $0 \cdot 05 \pm 0 \cdot 300$ & 0.983 \\
\hline \multicolumn{4}{|c|}{ DURING INTERVENTION } \\
\hline Vital signs & $1 \cdot 22 \pm 0 \cdot 609$ & $1 \cdot 47 \pm 0 \cdot 522$ & $0 \cdot 014$ \\
\hline Irritability & $0 \cdot 80 \pm 0 \cdot 389$ & $0 \cdot 91 \pm 0 \cdot 324$ & $0 \cdot 077$ \\
\hline Facial expression & $1 \cdot 20 \pm 0 \cdot 609$ & $1 \cdot 47 \pm 0 \cdot 502$ & $0 \cdot 003$ \\
\hline Behavior state & $0.73 \pm 0.635$ & $1 \cdot 35 \pm 0 \cdot 644$ & $0 \cdot 000$ \\
\hline Tone & $0 \cdot 64 \pm 0 \cdot 63$ & $0 \cdot 74 \pm 0 \cdot 438$ & $0 \cdot 082$ \\
\hline NPASS & $4 \cdot 62 \pm 2 \cdot 137$ & $5 \cdot 94 \pm 1 \cdot 899$ & $0 \cdot 000$ \\
\hline \multicolumn{4}{|c|}{ AFTER INTERVENTION } \\
\hline NPASS & $0 \cdot 55 \pm 0.954$ & $0 \cdot 64 \pm 1 \cdot 115$ & 0.700 \\
\hline
\end{tabular}

\section{Discussion:-}

Venepuncture is the one of the most common recurring painful health-related procedures in clinical practice. Various measures to reduce pain during venepuncture have been explored, including positioning and restraining the neonate in relatively flexed posture, kangaroo care, breastfeeding, use of oral analgesics, oral sucrose / saccharine solutions, tactile stimulation, skin-cooling techniques, skin-to-skin care, non nutritive sucking pacifiers, music therapy, etc ${ }^{(7-12)}$. Music therapy offers a safe and harmless intervention for reducing pain in neonates.

Joanne Loewy ${ }^{16}$ recorded use of culturally based musical tunes in the form of lullabies can improve neonatal function and hence in our study we used lullabies in Tamil language as most of the patient population visiting the hospital spoke Tamil language.

In our study the peak HR(heart rate) was lowest in the music group when compared to mother's voice and control group. The peak HR in the mother's voice group was lower than the control group. This signifies that both music and mother's voice decrease the heart rate during painful intervention and music had more positive effect than prerecorded mother's voice infant directed speech. These findings were in consistent with the study by Coleman et al ${ }^{17}$, Arnon et $\mathrm{al}^{18}$ where there was decrease in heart rate after the neonates were exposed to music. Statistically significant difference was found with regard to heart rate when music intervention was done in studies conducted by McIntosh et $\mathrm{al}^{19}$ and Bo LK ${ }^{20}$.

In our study, the music group had better oxygen saturation than control group with a p value of $0 \cdot 000$. Similar findings were found in Cassidy et al's ${ }^{21}$ study where there was statistically significant difference between recorded music and control group. In studies by Burke et $\mathrm{al}^{22}$, Chou et $\mathrm{al}^{23}$ and Standley et $\mathrm{al}^{24}$, the degree of fall of oxygen saturation was less in music group when compared to the control group.Caine et $\mathrm{al}^{25}$, Collins et $\mathrm{al}^{26}$, Whipple et al ${ }^{(27}$, Butt et $\mathrm{al}^{28}$ and Arnon et $\mathrm{al}^{18}$ recorded statistically significant difference in the behavioural parameters between the mother's group, music group and the control group. 
Our study showed significant improvement in all five parameters of Neonatal pain, agitation and sedation scale (NPASS); i.e., facial expression, cry and movements and also in duration of crying spells. There was statistically significant difference in the peak HR, RR(respiratory rate), lowest recorded oxygen saturation, behavioural parameters and NPASS during intervention between the music and control groups. There was statistically significant difference in the maximum NPASS, peak HR, peak RR, least recorded and all the behavioural parameter between control and mother's voice group.

\section{Proposed mechanism of action of music Therapy:-}

When auditory stimuli of music passes through the sound pathway to the cerebral cortex, there is reduction in the signalling in the amygdale. The reduced signalling of amygdale causes reduced level of stimulation of the hypothalamus, pituitary and endocrine glands. Hence there is decreased secretion of the cortisol and glucocorticoids thereby having effect on the autonomic system ${ }^{29}$. This explains the lower heart rate and better oxygen saturation in the music therapy group when compared with the control group. The underlying mechanism is explained by Farhat et $\mathrm{al}^{30}$ that music has its effects on the limbic and the autonomic system thus music reduces the stress and inducing comfort and relaxation in neonates.

Limitation of our study was the fact that the study was conducted in NICU and not in a sound proof room. Blinding could not be done in this study.

\section{Conclusion:-}

Music and mother's voice reduce the pain perception in neonates during venepuncture and they have beneficial effects on the physical and behavioural parameters. Pre recorded music is better than mother's voice in decreasing pain perception. Hence for routine painful procedures like venepuncture, music therapy could be helpful in neonates in reducing the pain perception.

\section{References:-}

1. Bellieni CV, Buonocore G, Nenci A, Franci N, Cordelli DM, Bagnoli F. Sensorial Saturation: An Effective Analgesic Tool for Heel-Prick in Preterm Infants: A Prospective Randomized Triall. Biol Neonate. 2001;80(1):15-8.

2. Simons SHP, Dijk M van, Anand KS, Roofthooft D, al et. Do We Still Hurt Newborn Babies?: A Prospective Study of Procedural Pain and Analgesia in Neonates. Arch Pediatr Adolesc Med. 2003 Nov;157(11):1058-64.

3. Anand KJS, Scalzo FM. Can Adverse Neonatal Experiences Alter Brain Development and Subsequent Behavior? Biol Neonate. 2000;77(2):69-82.

4. Kalpakidou AK, Allin MP, Walshe M, Giampietro V, Nam K, McGuire P, et al. Neonatal Brain Injury and Neuroanatomy of Memory Processing following Very Preterm Birth in Adulthood: An fMRI Study. PLoS ONE [Internet]. 2012 Apr 20 [cited 2015 Jul 14];7(4). Available from: http://www.ncbi.nlm.nih.gov/pmc/articles/PMC3332056/

5. Özdemir FK, Tüfekci FG. The effect of using musical mobiles on reducing pain in infants during vaccination. J Res Med Sci Off J Isfahan Univ Med Sci. 2012 Jul;17(7):662-7.

6. C Celeste Johnston FF. Recorded maternal voice for preterm neonates undergoing heel lance. Adv Neonatal Care Off J Natl Assoc Neonatal Nurses. 2007;7(5):258-66.

7. Azarmnejad E, Sarhangi F, Javadi M, Rejeh N. The Effect of Mother's Voice on Arterial Blood Sampling Induced Pain in Neonates Hospitalized in Neonate Intensive Care Unit. Glob J Health Sci. 2015;7(6):44088.

8. Krueger C, Parker L, Chiu S-H, Theriaque D. Maternal Voice and Short-Term Outcomes in Preterm Infants. Dev Psychobiol. 2010 Mar;52(2):205-12.

9. Hummel P, Lawlor-Klean P, Weiss MG. Validity and reliability of the N-PASS assessment tool with acute pain. J Perinatol Off J Calif Perinat Assoc. 2010 Jul;30(7):474-8.

10. Ludington-Hoe SM, Hosseini R, Torowicz DL. Skin-to-skin contact (Kangaroo Care) analgesia for preterm infant heel stick. AACN Clin Issues. 2005 Sep;16(3):373-87.

11. Johnston CC, Filion F, Campbell-Yeo M, Goulet C, Bell L, McNaughton K, et al. Kangaroo mother care diminishes pain from heel lance in very preterm neonates: a crossover trial. BMC Pediatr. 2008;8:13.

12. Huang C-M, Tung W-S, Kuo L-L, Ying-Ju C. Comparison of pain responses of premature infants to the heelstick between containment and swaddling. J Nurs Res JNR. 2004 Mar;12(1):31-40.

13. Liaw J-J, Yang L, Ti Y, Blackburn ST, Chang Y-C, Sun L-W. Non-nutritive sucking relieves pain for preterm infants during heel stick procedures in Taiwan. J Clin Nurs. 2010 Oct;19(19-20):2741-51. 
14. Lorch CA, Lorch V, Diefendorf AO, Earl PW. Effect of Stimulative and Sedative Music on Systolic Blood Pressure, Heart Rate, and Respiratory Rate in Premature Infants. J Music Ther. 1994 Jun 20;31(2):105-18.

15. Malone AB. The Effects of Live Music on the Distress of Pediatric Patients Receiving Intravenous Starts, Venipunctures, Injections, and Heel Sticks. J Music Ther. 1996 Mar 20;33(1):19-33.

16. Loewy J, Stewart K, Dassler A-M, Telsey A, Homel P. The effects of music therapy on vital signs, feeding, and sleep in premature infants. Pediatrics. 2013;131(5):902-18.

17. Coleman JM, Pratt RR, Stoddard RA, Gerstmann DR, Abel H-H. The effects of the male and female singing and speaking voices on selected physiological and behavioral measures of premature infants in the intensive care unit. Int J Arts Med [Internet]. 1997 [cited 2015 Sep 13]; Available from: http://psycnet.apa.org/psycinfo/1998-10127-001

18. Arnon S, Shapsa A, Forman L, Regev R, Bauer S, Litmanovitz I, et al. Live Music Is Beneficial to Preterm Infants in the Neonatal Intensive Care Unit Environment. Birth. 2006;33(2):131-6.

19. McIntosh N, Van Veen L, Brameyer H. The pain of heel prick and its measurement in preterm infants. Pain. 1993 Jan;52(1):71-4.

20. Bo LK, Callaghan P. Soothing pain-elicited distress in Chinese neonates. Pediatrics. 2000 Apr;105(4):E49.

21. Cassidy JW. The Effect of Decibel Level of Music Stimuli and Gender on Head Circumference and Physiological Responses of Premature Infants in the NICU. J Music Ther. 2009 Fall;46(3):180-90.

22. Burke M, Walsh J, Oehler J, Gingras J. Music therapy following suctioning: four case studies. Neonatal Netw NN. 1995 Oct;14(7):41-9.

23. Chou L-L, Wang R-H, Chen S-J, Pai L. Effects of music therapy on oxygen saturation in premature infants receiving endotracheal suctioning. J Nurs Res JNR. 2003 Sep;11(3):209-16.

24. Standley JM. The effect of music and multimodal stimulation on responses of premature infants in neonatal intensive care. Pediatr Nurs. 1998 Dec;24(6):532-8.

25. Caine J. The effects of music on the selected stress behaviors, weight, caloric and formula intake, and length of hospital stay of premature and low birth weight neonates in a newborn intensive care unit. J Music Ther. 1991;28(4):180-92.

26. Collins SK, Kuck K. Music therapy in the neonatal intensive care unit. Neonatal Netw NN. 1991 Mar;9(6):236.

27. Whipple J. The effect of music-reinforced nonnutritive sucking on state of preterm, low birthweight infants experiencing heelstick. J Music Ther. 2008;45(3):227-72.

28. Butt ML, Kisilevsky BS. Music modulates behaviour of premature infants following heel lance. Can J Nurs Res Rev Can Rech En Sci Infirm. 2000 Mar;31(4):17-39.

29. Music therapy and pain management in pediatric patients undergoing painful procedures: A review of the literature and a call for research pp. 7-16 [Internet]. [cited 2015 Dec 9]. Available from: https://www.novapublishers.com/catalog/product_info.php?products_id=17035

30. Farhat A, Amiri R, Karbandi S, Esmaily H, Mohammadzadeh A. The effect of listening to lullaby music on physiologic response and weight gain of premature infants. J Neonatal-Perinat Med. 2010 Jan 1;3(2):103-7. 